\section{Novel technique to relax the lower esophageal sphincter during challenging peroral endoscopic myotomy (POEM)}

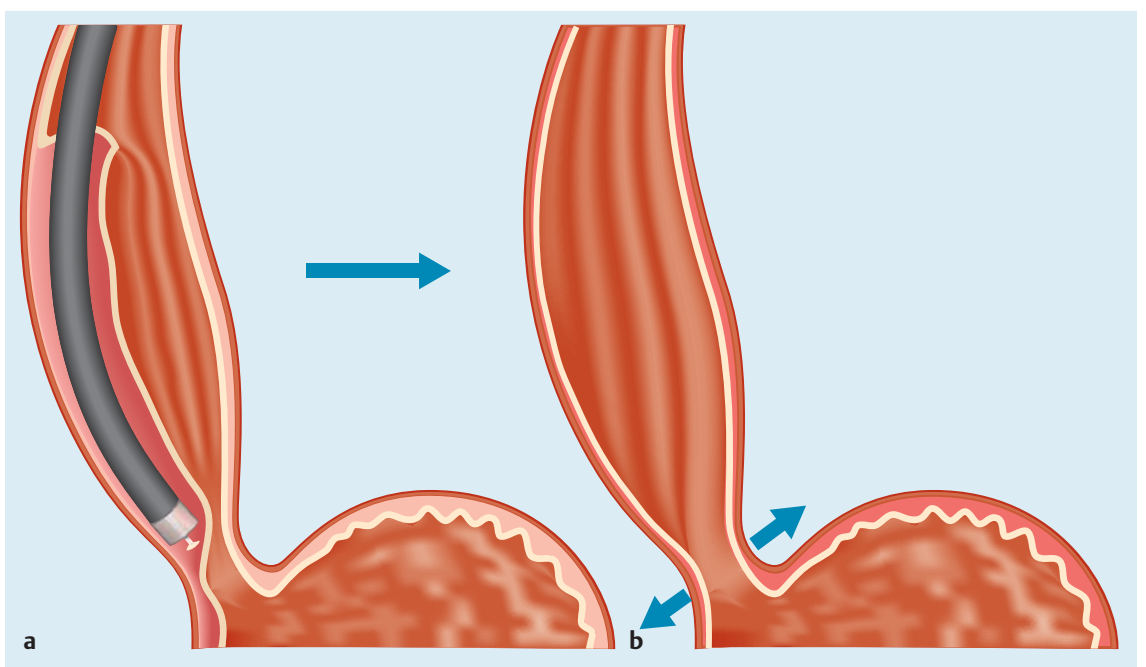

Fig. 1 Illustration of the effect of amyl nitrite on lower esophageal sphincter relaxation during peroral endoscopic myotomy (POEM).

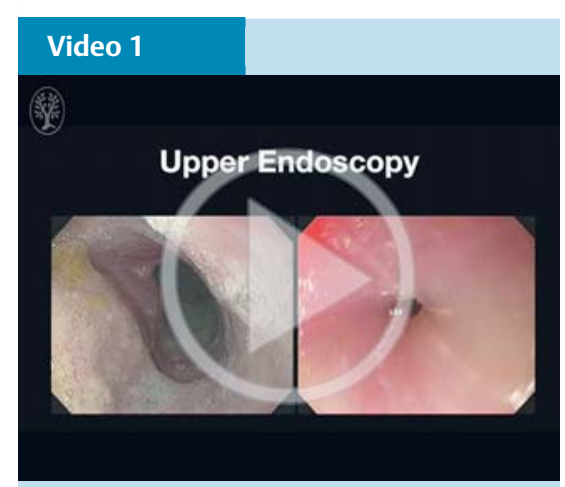

The use of amyl nitrite inhalation to relax the lower esophageal sphincter and facilitate submucosal tunneling in two patients with achalasia.

Amyl nitrite is easily administered and is a potent short-acting smooth muscle relaxant. Therefore, it can be used to relax the lower esophageal sphincter (LES) during submucosal tunneling in peroral endoscopic myotomy (POEM) ( $\bullet$ Fig. 1) [1,2]. One study demonstrated that the diameter of the LES increased by $>3 \mathrm{~mm}$ in patients with idiopathic achalasia in response to amyl nitrite [3]. POEM involves the creation of a submucosal tunnel, for which dissection of fibers should be car- ried out close to the muscle layer to avoid mucosal injury. When the LES is tight, this dissection of the fibers can be challenging to perform safely without risking mucosal injury. Video 1 demonstrates the use of amyl nitrite inhalation to relax the LES and facilitate submucosal tunneling in two patients.

The first patient was a 59-year-old man who underwent POEM for type III achalasia. During tunneling, the distal esophagus and LES were spastic, which inhibited the advancement of the endoscope. The decision was made to use amyl nitrite. During its administration, the patient's heart rate increased by 10 beats per minute (bpm) from a baseline of $70 \mathrm{bpm}$ and his blood pressure (BP) decreased to $95 / 68 \mathrm{mmHg}$ from $117 / 70 \mathrm{mmHg}$. The second patient was a 38-year-old woman who underwent POEM for type II achalasia. During POEM her LES was found to be tight, which prevented effective and safe tunneling. When amyl nitrite was given, her heart rate increased by $10 \mathrm{bpm}$ from baseline and her systolic BP dropped to $80 \mathrm{mmHg}$ from a baseline of $116 \mathrm{mmHg}$.

Both patients were admitted to the hospital for observation following their procedures. They were discharged home on soft diet and returned to clinic 4 weeks later with complete resolution of their symptoms.

We conclude that amyl nitrite is a safe and effective method to relax the LES. This technique may be utilized in patients where the safe creation of a submucosal tunnel through the LES might otherwise not have been possible.

\section{Endoscopy_UCTN_Code_TTT_1AO_2AN}

Competing interests: Dr. Khashab is a consultant for Boston Scientific. All other authors have no relevant disclosures.

\section{Majidah Bukhari ${ }^{1}$, Vivek Kumbhari ${ }^{1}$, Yamile Haito-Chavez ${ }^{1}$, Yen-I Chen ${ }^{1}$, Saowanee Ngamruengphong ${ }^{1}$, Payal Saxena ${ }^{2}$, Mouen A. Khashab ${ }^{1}$}

${ }^{1}$ Department of Medicine and Division of Gastroenterology and Hepatology, The Johns Hopkins Medical Institutions, Baltimore, Maryland, USA

${ }^{2}$ Department of Medicine and Division of Gastroenterology and Hepatology, Royal Prince Alfred Hospital, Camperdown, New South Wales, Australia

\section{References}

1 Kahrilas PJ, Kishk SM, Helm JF et al. Comparison of pseudoachalasia and achalasia. Am J Med 1987; 82: 439-446

2 Gonzalez M, Mearin F, Vasconez $C$ et al. Oesophageal tone in patients with achalasia Gut 1997; 41: $291-296$

3 Dodds WJ, Stewart ET, Kishk SM et al. Radiologic amyl nitrite test for distinguishing pseudoachalasia from idiopathic achalasia. AJR Am J Roentgenol 1986; 146: 21 -23

\section{Bibliography}

Dol http://dx.doi.org/

10.1055/s-0042-109776

Endoscopy 2016; 48: E252

(c) Georg Thieme Verlag KG

Stuttgart · New York

ISSN 0013-726X

\section{Corresponding author}

\section{Mouen A. Khashab, MD}

Therapeutic Endoscopy

Johns Hopkins Hospital

Sheikh Zayed Bldg

Division of Gastroenterology and Hepatology

1800 Orleans Street, Suite 7125B

Baltimore

MD 21287

USA

Fax: +1-443-683-8335

mkhasha1@jhmi.edu 